\title{
Design of Management System under Fully Liberalizing the Power Generation and Utilization Plans for Operating Power Users
}

\author{
Dunnan Liu ${ }^{1}$, Zhixin Dong ${ }^{2, *}$ \\ ${ }^{1}$ North China Electric Power University, Beijing, 102206, China
}

\begin{abstract}
In June 2019, the National Development and Reform Commission announced the "Notice on Fully Liberalizing the Power Generation and Utilization Plans for Operating Power Users". With the liberalization of power generation and utilization plans for operating power users, the number of market entities participating in cross-province and cross-region transactions and the scale of transactions have increased, and power trading services are facing severe challenges. Therefore, it is necessary to improve the power market transaction management system and platform. There is an urgent need to build a multidimensional interactive power trading service system, to sort out and improve the business processes of market entity registration, transaction, settlement, and performance guarantee. And it is vital through the comprehensive upgrade and improvement of the trading platform functions to ensure the surge in marketoriented business demand. In addition, a market entity credit management system and contract performance evaluation mechanism should be established to strictly regulate the order of transactions in the electricity market.
\end{abstract}

\section{Introduction}

In order to promote the implementation of reforms, in recent years, the state has issued a series of policies, which aimed at advancing the reform of the electricity market, further delegating the development of electricity consumption plans, and forming a more complete electricity market-based trading mechanism. The existing power market operation and management mechanism gradually showed some deficiencies.

In the existing literature, literature [1] combined the characteristics of the new situation and proposed the construction principles of a new generation of power market operation and management mechanisms. Literature [2] aims to enhance the standardization of electricity market transactions and ensure the harmony and stability of the electricity transaction environment, and proposes to strengthen the supervision and supervision of the qualifications of electricity transaction entities. Literature [3] proposes to improve the credit system of electricity market-oriented transaction to ensure that market entities are more trustworthy. Literature [4] analyzes the construction plan of power sales management platform for power generation enterprises. However, there is a lack of relevant management system design for trans-provincial power market operation in the existing literature. Therefore, this article focuses on this aspect. It provides reference and guidance for the cross-province and cross-region transaction management of the electricity market under the new policy, which is of positive significance.

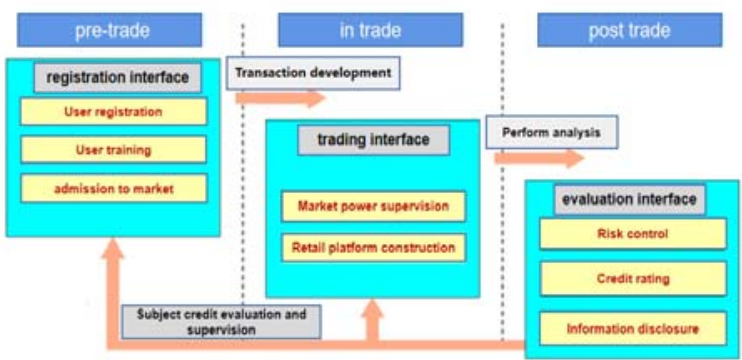

Figure 1. Analysis of management problems in the whole process of power transaction

\section{Design of the relevant access mechanism for users to participate in cross-province and cross-region transactions}

\subsection{The access conditions for cross-province and cross-region markets}

Cross-province and cross-region transactions are expected to further expand the scope of market transactions and use market means to achieve a broader "power resource sharing, power market sharing", and fundamentally promote the large-scale optimization of power resources and clean energy consumption.

\footnotetext{
${ }^{*}$ Corresponding author: dongzhixin10@163.com
} 
However, the implementation of cross-province and cross-region market-oriented transactions is much more difficult and complicated than intra-province transactions. Cross-province and cross-region transactions rely on stronger power channel guarantees, more advanced grid dispatching capabilities, more reasonable price mechanisms, and more efficient marketoriented transaction organizations.

(1)Market access conditions for power generation companies. The government clarifies that power generation companies that are consumed across provinces, power generation companies that are included in the provincial government' $s$ market transaction subject dynamic catalogue, and other governmentapproved power generation companies can enter the market. Power generation companies can entrust power grid agents, and renewable energy such as small hydropower, wind power, and photovoltaic power generation can also entrust power generation companies as agents. Self-provided power plants will not participate temporarily.

(2)Market access conditions for electricity sales companies. No special threshold requirements.

(3)Market access conditions for power users. No special threshold requirements.

The awakening of consciousness on the power generation side is early, but there are still obstacles in some provinces. How to go out of the province needs further consideration.

At the same time, for the user side, after meeting certain conditions, they can also go out of the province and realize cross-province and cross-region transactions through the agent transaction of the electricity sales company.

\subsection{Gradually releasing the development of power-side and user-side market entities to participate in cross-province power market access}

All entities should implement the inter-provincial medium and long-term power trading rules of the trading center for inter-provincial market members, open power users and power sales companies to participate in the inter-provincial power market, and promote the continued prosperity and development of inter-regional power market transactions. Then, in market transactions, fair treatment should be given to market entities on the power generation side, and more power generation companies should be opened to participate in transprovincial power market transactions.

(1) Encouraging the power generation side to participate in cross-province transactions. At present, western power generation companies have a strong sense of participating in market competition, but some power generation companies in the central and eastern provinces still have provincial barriers to participate in cross-province transactions. Power generation companies should be strongly encouraged to participate in provincial competition.
(1) No restrictions will be imposed on the basis of ensuring the safety of the power grid and the power supply needs of the province. (2)In accordance with the implementation rules for the management of entry and exit of power market entities, on the basis of meeting the entry conditions, the trading center further considers cross-subsidy fees and consumption weight allocation and other related indicators. (3)Each generating unit can participate in cross-province market transactions. The reference sequence for liberalization is: coal power, gas power, adjustable hydropower, nuclear power, nonregulated hydropower, wind power and photovoltaics. At the same time, large hydropower and nuclear power should be considered. Establish a priority power generation system simultaneously. (4) On the power generation side, except for the priority purchase and power generation part, the on-grid electricity price is determined by independent negotiation or market bidding, and the on-grid electricity price and the sales price are finally released.

(2)Gradually allow users to participate in crossprovince transactions. At present, the complete release of user-side participation in cross-province trades will have a greater impact on the power grid companies, power generation companies, user management, transmission channels, local taxation, and economic development in the user's province.

(1) At this stage, considering the impact of users' trips to the province and the limitations of current grid technical conditions, users should not conduct largescale cross-province transactions, but they can allow a small number of users to participate. For example, some new energy industries and industries with a small power consumption scale should try first, and encourage electric vehicles, port shore power and other power companies to participate in cross-province transactions. (2) With the continuous development of the electricity market in the future, certain access conditions can be set to advance steadily. Comprehensive consideration of cross-subsidy and renewable energy consumption weight indicators to gradually open the user side to participate in cross-province transactions. If users are fully liberalized to participate in cross-province transactions, they must verify cross-subsidy responsibilities based on the users' original catalog electricity prices.

\section{The electricity retail market management under the participation of all market entities}

\subsection{The connotation of retail management}

Regarding electricity sales companies and users, retail management has two main connotations: The electricity sales company realizes the management of entrusted users through the retail management platform. And through the retail management platform, registered users can realize all the businesses of entering the market, such as following the electricity sales company and 
completing the establishment of retail service relationships.

Electricity trading institutions can rely on electricity trading big data to establish an electricity market retail management platform to provide a better experience for the majority of market entities. They can develop relevant services from the aspects of market entity information management, retail service relationship management, transaction management and settlement management to promote the development of the retail market. The electricity market retail management platform developed by the Electricity Trading Center is committed to providing one-stop convenient services for market entities participating in the retail market, and promoting the formation of a benign interactive, stable and active electricity retail format. Finally, the goal of strengthening the management of all parties in the market, reducing costs, and improving efficiency is achieved.

In addition, the electricity market retail management platform serves electricity sales companies and users participating in the local electricity market. The core of its function is retail management, which provides "onestop" management for electricity sales companies and “one-stop” services for users.

\subsection{The retail management platform}

Through the online operation of the retail management platform of the electricity market, it helps the electricity sales companies to strengthen management and promote the active development of the retail market. With the further liberalization of the electricity retail market, the electricity retail market has gradually formed. On the basis of conducting demand surveys of power sales companies, the power trading center should fully rely on the power trading big data center to establish a power market retail management platform to provide a better experience for the majority of market entities and promote the active development of the retail market. Electricity trading institutions can rely on electricity trading big data to establish an electricity market retail management platform to provide a better experience for the majority of market entities. For example, relevant services are developed from the aspects of market entity information management, retail service relationship management, transaction management, and settlement management to promote the development of the retail market.

\subsection{The main functions of retail management platform}

The main functions of the retail management platform include: market entity information management, retail service relationship management, transaction management, and settlement management.

(1) Information management of market entities. The electricity sales company can view the file materials during the user agent period, including account number, name, voltage level, electricity consumption category, electricity consumption, etc. Users can view the file information of the electricity sales company. Electricity sales companies can also display their styles and independently display relevant information about the company.

(2) Retail service relationship management. Electricity sales companies and power users can automatically and quickly generate retail service contracts on the platform. The sales companies and users confirm the retail service contracts and establish retail service relationships. At the same time, electricity sales companies and electricity users can inquire about their retail service contracts and process information data on the platform.

(3) Transaction management. The retail management platform supports users to $\log$ in to fill in the requirements, and the retail company can summarize and generate the data to be declared according to the requirements. At the same time, it also supports electricity sales companies to view the volume and price information allocated to users in the retail market.

(4) Settlement management. Support electricity sales companies and users to view settlement statements on the retail management platform. The service income function between the electricity sales company and the user can customize the income model, which supports the electricity sales company to configure the existing parameters in the market, and the trading center will issue the settlement basis according to the custom income model of the electricity sales company.

\section{Power transaction management with the participation of all market entities}

\subsection{Construction of market risk management and control system}

Through resource sharing and centralized management of market transaction information at all levels, it provides an environmental basis for the development of cross-province and cross-region transactions, and provides a reliable basis for analysis and decisionmaking related to market transactions. Cross-province and cross-region transactions are mainly to monitor the transaction costs, electricity prices, and other factors that directly affect the income of power companies and the changes in the power grid supply and demand situation, and statistically analyze the status of cross-province and cross-region transactions.

The cross-regional and cross-provincial transaction management and control process includes three stages: pre-potential transaction space analysis, in-process transaction process control, and post-event transaction execution. The key nodes of cross-province and crossregion transaction control are classified as potential pretransaction analysis, transaction behavior, Four nodes are evaluated after transaction execution and transaction results.

(1) Analysis before the transaction. It mainly uses the control of relevant information in the transaction space to tap the potential of trans-regional and trans-provincial 
transactions, and realize the optimized combination of trans-regional and trans-provincial transactions, including the load level of each region, the level of power generation costs, the balance of supply and demand, the capacity of transmission channels and the remaining power generation Ability etc.

(2) Evaluation indicators of trading behavior. It mainly controls the transaction process and strengthens the compliance management of the transaction, including the compliance identification of relay transactions, hedging transactions, and pairing transactions.

(3) Evaluation indicators for transaction execution. It mainly controls the execution process and plan arrangement of the transaction to ensure the reasonable execution of the transaction and reduce the deviation caused by the actual execution.

(4) Evaluation indicators of transaction results. It mainly analyzes the costs and benefits generated after transaction settlement, evaluates the economic and social value of cross-province and cross-region transactions, and guides the power purchase strategy of crossprovince and cross-region transactions.

\subsection{Improvement of the credit evaluation system}

The National Development and Reform Commission and the National Energy Administration, together with relevant parties, have accelerated the construction of a credit system for power market entities. They established credit evaluation index systems for different market entities, introduced national industry associations, credit service agencies, and power trading institutions, established a credit evaluation system, carried out data collection for direct electricity transactions, and implemented annual information publicity by market entities.

At the same time, it also includes mechanisms for joint incentives for trustworthiness and joint punishment for untrustworthiness to strengthen credit awareness and restrict market entities with bad credit records from participating in electricity market-oriented transactions.

The establishment and improvement of red list and black list systems. For market entities that comply with the law and have good credit ratings or above, be included in the red list, and study incentives such as giving priority to market transactions under the same conditions; Market entities that violate trading rules and have dishonesty behaviors are included in bad credit records, the circumstances are particularly serious or they refuse to rectify, they will be included in the blacklist of dishonest companies after publicity and other relevant procedures; market entities that are forced to withdraw are directly included in the black list of dishonest companies List.

\subsection{The electricity transaction information disclosure}

First of all, information disclosure should fully and publicly display information on grid congestion, power generation capacity and other information needed to conduct transactions. Secondly, a regulatory mechanism for information security and market order should be established. Scientific information disclosure and regulatory mechanisms should be used to promote market information symmetry and form a fair, just, and open effective and active market. Finally, the subjects participating in cross-province transactions need to disclose their credit information to the provinces that sell electricity. In the same way, the purchaser must also disclose relevant information. The trading center shall clarify the division of responsibilities, information classification, information disclosure content, method and cycle of information disclosure in cross-province and cross-region power trading activities.

With the institutionalization and standardization of market information disclosure, the electricity trading environment will become more transparent, which will help maintain market order.

\section{Conclusion}

Based on the impact of the new policy, this paper puts forward relevant countermeasures to strengthen the cross-province and cross-region power transaction management system. Firstly, relevant designs were carried out from the access to the electricity market. Secondly, relevant suggestions were made for the management and platform of the electricity retail market. At the same time, it is necessary to accelerate the construction of the market risk control system, improve the credit evaluation system, which provides reference and guidance for the electricity market under the new policy.

\section{Acknowledgement}

The State Grid Corporation Headquarters Science and Technology Project "Research on Supporting Technology of Integrated Energy Market Operation and Service Based on Value Sharing" (5400-202018202A-00-00).

\section{References}

1. Wang, N., Zhou, X.Q. (2020) Research and Prospects on the Operation and Management Mechanism of the New Generation Electricity Market. J. Journal of Science \& Technology Economics, 28(29): 205+204.

2. Zou, L.W. (2020) The design and implementation of Yunnan power market transaction management system. D. Shandong University.

3. Jin, Y., Xia, Z.J., Wang, H.H., Wang, P., Zang Z.B. (2020) Considerations on the credit management of power market-oriented transaction entities. J. Enterprise Technology and Development, (05): 245246.

4. Chen, Z.F. (2019) Compliance management is urgently needed in the electric power field. J. Popular Electricity, 34(05): 3-5. 